\title{
Value of serum pregnancy-associated plasma protein A for predicting cardiovascular events among patients presenting with cardiac chest pain
}

\author{
Stephan von Haehling MD PhD, Wolfram Doehner MD PhD, Ewa A. Jankowska MD PhD, \\ Piotr Ponikowski MD PhD, Konstantinos Stellos MD, Valentina O. Puntmann MD, Eike Nagel MD, \\ Stefan D. Anker MD PhD, Meinrad Gawaz MD, Boris Bigalke MD
}

\section{- Abstract}

Background: Pregnancy-associated plasma protein A (PAPP-A) has been suggested as a candidate marker for the identification of unstable plaques in coronary arteries. We assessed the value of PAPP-A for predicting short-term cardiovascular events in a large cohort of patients presenting with cardiac chest pain.

Methods: We included consecutive patients who presented to a teaching hospital in Germany with chest pain of cardiac origin confirmed by coronary angiography. We analyzed PAPP-A levels from serum samples drawn within 30 minutes after arrival in the emergency department or in the catheterization laboratory. Patients were followed for 90 days or until death for major adverse cardiovascular events, defined as the combined outcome of stent thrombosis, myocardial (re)infarction, ischemic stroke or cardiovascular-related death.

Results: A total of 2568 patients (mean age [ \pm standard deviation (SD)] $68 \pm 11$ years; $74 \%$ male) presented with cardiac chest pain: $55 \%$ had stable angina and $45 \%$ had acute coronary syndrome. The PAPP-A levels ranged from 4 to $2154 \mathrm{mIU} / \mathrm{L}$ (median $14.0 \mathrm{mlU} / \mathrm{L}$, interquartile range 9.3-25.2 mIU/L). Major adverse cardiovascular events occurred in 203 patients (7.9\%). The mean PAPP-A level was higher among patients who had an event than among those who did not $(62 \pm 156$ v. $21 \pm 23 \mathrm{mIU} / \mathrm{L}$ $p<0.001)$. In a multivariable analysis, PAPP-A remained a significant independent predictor of the primary outcome within 90 days (hazard ratio per 1 SD increase in PAPP-A level 1.96, $95 \%$ confidence interval 1.74-2.21). The optimal prognostic cutoff value was a PAPP-A level of $34.6 \mathrm{mlU} / \mathrm{L}$.

Interpretation: Higher levels of serum PAPP-A were independently associated with an increased short-term risk of cardiovascular events in patients presenting with cardiac chest pain. Further studies are required to validate the use of PAPP-A in routine clinical practice to predict future cardiovascular events.
$\mathrm{C}$ oronary artery disease is the leading single cause of death in the Western world. ${ }^{1}$ Patients with coronary artery disease cycle between asymptomatic phases, episodes of progressive angina and acute coronary syndromes. ${ }^{2}$ Cardiac troponin levels have a high sensitivity and specificity in the diagnosis of non-STsegment elevation myocardial infarction. ${ }^{3-5}$ However, a large number of patients at risk of major coronary events do not present with myocardial necrosis and cannot be identified by troponin elevations. Markers of plaque instability may be helpful in this regard.

An interesting candidate for the identification of unstable plaques is the zinc-binding metalloproteinase pregnancy-associated plasma protein A (PAPP-A).$^{6-8}$ It was identified in 1972 in blood samples from pregnant women, ${ }^{9}$ and it is widely used in the screening for fetal trisomy. ${ }^{10,11}$ However, the term "pregnancy-associated plasma protein A" is misleading, because the peptide is not secreted only during pregnancy. Interest in cardiovascular applications first arose in 2001, when it became clear that the peptide is abundantly expressed in eroded and ruptured, but not in stable, atherosclerotic plaques. ${ }^{12} \mathrm{Sev}$ eral authors have later pursued the idea that PAPP-A might help to stratify the risk of major adverse cardiovascular events in patients with coronary artery disease. However, earlier studies were limited by sample size or by the number of clinical events.

We sought to evaluate the value of PAPP-A for predicting major adverse cardiovascular
Competing interests: See end of article.

This article has been peer reviewed.

Correspondence to: Stephan von Haehling, stephan.von.haehling@web.de

CMAJ 2013. DOI:10.1503 /cmaj.110647 
events in a large sample of 2568 consecutive patients who presented with cardiac chest pain.

\section{Methods}

\section{Patient selection}

We evaluated consecutive patients who presented with chest pain to the University Hospital Tübingen, Germany, between December 2007 and April 2009. A cardiac cause of chest pain was assumed unless proven otherwise and was confirmed with coronary angiography.

\section{Clinical evaluation}

All patients underwent coronary angiography within 24 hours after arrival, either for suspected acute coronary syndrome or as part of an elective admission in patients with stable angina. Acute coronary syndrome was defined according to the joint guidelines of the American Heart Association and the American College of Cardiology, ${ }^{13}$ with a diagnostic threshold for troponin I of $0.04 \mathrm{ng} / \mathrm{mL}$ or higher. Stable angina pectoris was defined as symptoms of angina pectoris without

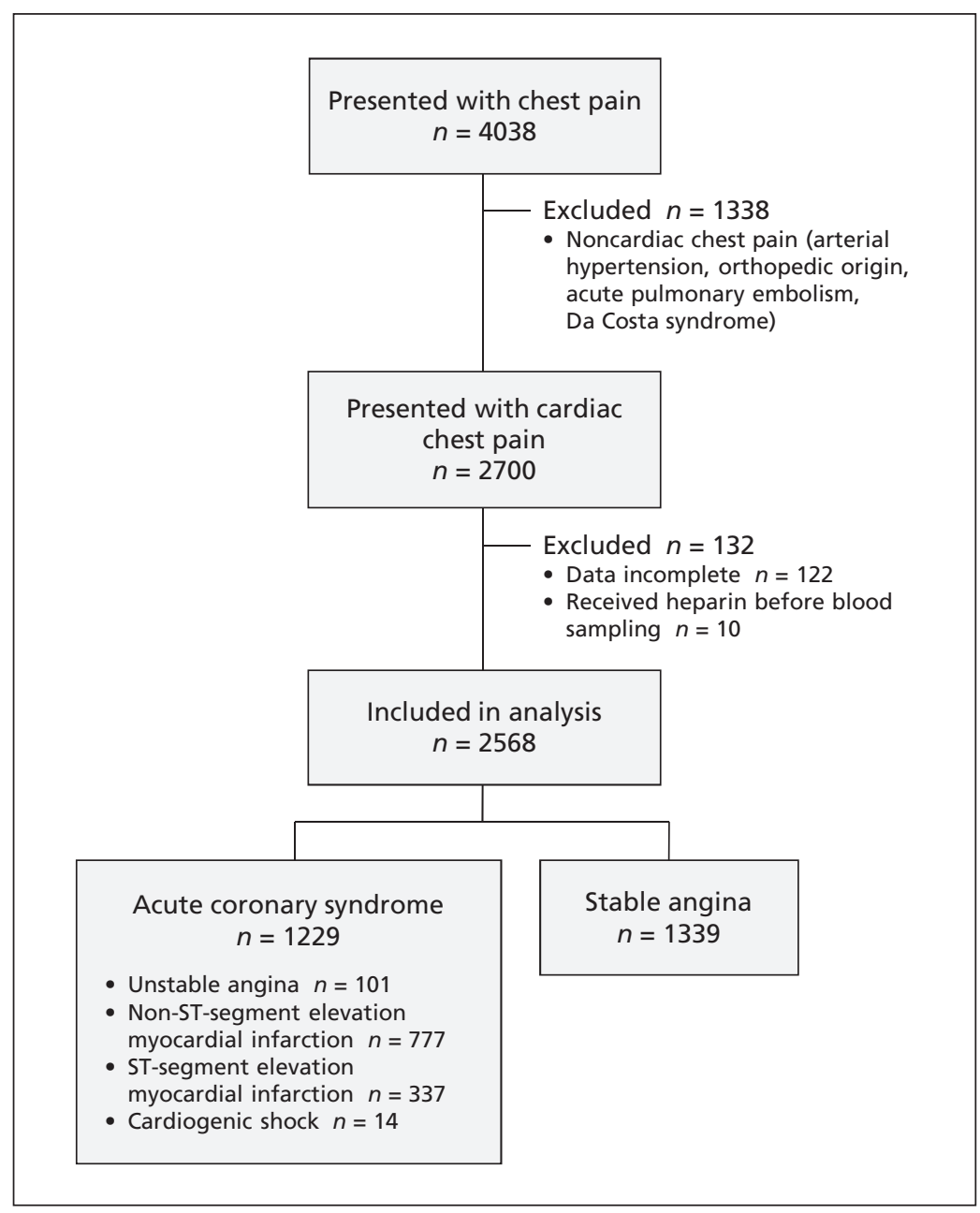

Figure 1: Selection of patients. progression and with stable intensity and a troponin I level below $0.04 \mathrm{ng} / \mathrm{mL}$ before cardiac catheterization.

All patients underwent echocardiography within 48 hours after initial presentation. The degree of left ventricular impairment was classified according to the left ventricular ejection fraction: severe impairment (left ventricular ejection fraction $<35 \%$ ), moderate impairment (35\%-44\%), mild impairment $(45 \%-59 \%)$ or no impairment $(\geq 60 \%)$.

All patients were followed up by telephone interview or outpatient office visit for 90 days or until death. No patient was lost to follow-up.

\section{Biochemical analysis}

Venous blood was drawn from an antecubital vein for routine clinical assessments and as part of a prospective biomarker research project. For our study, we excluded patients who had blood samples collected after the administration of heparin, because PAPP-A is known to interact with heparin. ${ }^{14}$ Serum samples were immediately centrifuged and stored at $-80^{\circ} \mathrm{C}$ for later analysis.

We analyzed serum values of creatine kinase, C-reactive protein and creatinine using standard laboratory assays. Troponin I was analyzed using a highly sensitive assay (Troponin I-Ultra assay on the ADVIA Centaur immunoanalyzer, Siemens AG, Eschborn, Germany). If more than one measurement was available for the entire hospital stay, the respective peak values were entered into the analysis. For PAPP-A assessment, an additional blood sample was filled into 5-mL pyrogen-free serum vials. Blood samples for PAPP-A analysis were drawn within 30 minutes after arrival to the emergency department or in the catheterization laboratory, whichever came first. PAPP-A serum values were analyzed using an automated immunofluorescent assay (Kryptor PAPP-A automated immunofluorescent assay, Thermo Fisher Scientific, BRAHMS GmbH, Hennigsdorf, Germany). The functional assay sensitivity (interassay coefficient of variance $<3 \%$ ) is $4 \mathrm{mIU} / \mathrm{L}$. According to the manufacturer, the normal serum value in men and nonpregnant women is $<14 \mathrm{mIU} / \mathrm{L}$. Physicians involved in caring for the patients or who performed follow-up investigations were unaware of the respective PAPP-A serum values.

\section{Ethics approval}

The study design was approved by the Clinical Ethics Committee of the University Hospital Tübingen, and all patients provided written informed consent. 


\section{Outcome measure}

The primary outcome measure was a combined outcome of stent thrombosis, myocardial (re)infarction, ischemic stroke or cardiovascularrelated death.

\section{Statistical analysis}

Data are expressed as mean \pm standard deviation (SD). Normal distribution was assessed using the Kolmogorov-Smirnov test, and non-normally distributed data were log-transformed to achieve normal distribution. We used the $\chi^{2}$ test, Student unpaired $t$-test, and analysis of variance with the Fisher predicted least significant difference (post hoc) test to compare differences between groups. Univariable regression analyses were performed to assess factors that independently predicted PAPP-A levels. The association of baseline vari- ables with survival was assessed by means of Cox proportional hazard analysis (single predictor and multivariable analysis). Hazard ratios (HRs) and 95\% confidence intervals (CIs) for risk factors and significance level for $\chi^{2}$ (likelihood ratio test) were calculated. For variables that were included twice in the unadjusted model (as $\log$ and continuous variables), the variable with the higher level of significance in the unadjusted model, as judged by the $\chi^{2}$ value, was chosen for the multivariable model. To estimate the influence of risk factors on the occurrence of the primary outcome at 90 days, we constructed Kaplan-Meier cumulative survival curves for illustrative purposes and compared them using the log-rank test. The optimal prognostic cut-off value was defined as the highest product of sensitivity multiplied by specificity. In all analyses,

Table 1: Baseline characteristics of 2568 patients presenting with cardiac chest pain

\begin{tabular}{|c|c|c|c|c|}
\hline \multirow[b]{2}{*}{ Parameter } & \multicolumn{3}{|c|}{ Primary diagnosis; no. (\%) of patients or mean \pm SD } & \multirow[b]{2}{*}{$p$ valuet } \\
\hline & $\begin{array}{c}\text { All } \\
n=2568\end{array}$ & $\begin{array}{l}\text { Stable angina } \\
\quad n=1339\end{array}$ & $\begin{array}{l}\text { Acute coronary } \\
\text { syndrome } \\
n=1229\end{array}$ & \\
\hline Age, yr & $68.4 \pm 11.2$ & $68.4 \pm 9.9$ & $68.3 \pm 12.4$ & 0.7 \\
\hline Male sex & $1905(74.2)$ & $1025(76.5)$ & $880(71.6)$ & 0.005 \\
\hline $\mathrm{BMI}, * \mathrm{~kg} / \mathrm{m}^{2}$ & $\begin{array}{c}n=1336 \\
27.7 \pm 4.6\end{array}$ & $\begin{array}{c}n=662 \\
28.2 \pm 4.8\end{array}$ & $\begin{array}{c}n=674 \\
27.3 \pm 4.5\end{array}$ & $<0.001$ \\
\hline \multicolumn{5}{|l|}{ Left ventricular impairment } \\
\hline None & $1259(50.8)$ & $750(57.9)$ & $509(43.0)$ & \multirow[t]{4}{*}{$<0.001$} \\
\hline Mild & $577(23.3)$ & $282(21.8)$ & $295(24.9)$ & \\
\hline Moderate & $402(16.2)$ & $160(12.4)$ & $242(20.4)$ & \\
\hline Severe & $242(9.8)$ & $103(8.0)$ & $139(11.7)$ & \\
\hline Coronary artery disease & $n=940$ & $n=547$ & $n=393$ & 0.4 \\
\hline $\begin{array}{l}\text { No. of affected coronary vessels } \\
\text { per patient }\end{array}$ & $2.3 \pm 0.8$ & $2.3 \pm 0.8$ & $2.3 \pm 0.8$ & \\
\hline Underwent coronary intervention & $919(97.7)$ & $526(96.2)$ & $393(100.0)$ & $<0.001$ \\
\hline \multicolumn{5}{|l|}{ Type of intervention performed } \\
\hline PTCA only & $18(2.0)$ & 17 (3.2) & $2(0.5)$ & \multirow[t]{4}{*}{$<0.001$} \\
\hline Bare metal stent & $790(86.0)$ & $503(95.6)$ & $286(72.7)$ & \\
\hline Drug-eluting stent & $79(8.6)$ & $3(0.6)$ & $76(19.3)$ & \\
\hline Both types of stents & $31(3.4)$ & $3(0.6)$ & $29(7.4)$ & \\
\hline C-reactive protein, mg/L & $\begin{array}{l}n=1998 \\
37 \pm 63\end{array}$ & $\begin{array}{l}n=876 \\
14 \pm 30\end{array}$ & $\begin{array}{l}n=1122 \\
56 \pm 74\end{array}$ & $<0.001$ \\
\hline Creatine kinase, U/L & $\begin{array}{c}n=2272 \\
521 \pm 1259\end{array}$ & $\begin{array}{c}n=1106 \\
145 \pm 246\end{array}$ & $\begin{array}{c}n=1166 \\
877 \pm 1666\end{array}$ & $<0.001$ \\
\hline Troponin I, $\mu \mathrm{g} / \mathrm{L}$ & $\begin{array}{c}n=2553 \\
16.6 \pm 60.7\end{array}$ & $\begin{array}{l}n=1339 \\
0.8 \pm 7.3\end{array}$ & $\begin{array}{c}n=1214 \\
33.7 \pm 84.5\end{array}$ & $<0.001$ \\
\hline Creatinine, $\mu \mathrm{mol} / \mathrm{L}$ & $\begin{array}{c}n=2326 \\
110.2 \pm 73.1\end{array}$ & $\begin{array}{c}n=1160 \\
105.0 \pm 66.2\end{array}$ & $\begin{array}{c}n=1166 \\
115.4 \pm 79.0\end{array}$ & $<0.001$ \\
\hline $\begin{array}{l}\text { Note: } \mathrm{BMI}=\text { body mass index, PTCA = percut } \\
{ }^{*} \mathrm{BMI} \text { values were available for } 1336 \text { patients } \\
\text { tFor comparison between patients with stab } \\
t \text {-test or } \chi^{2} \text { test). }\end{array}$ & $\begin{array}{l}\text { eous translumina } \\
62 \text { with stable an } \\
\text { angina and those }\end{array}$ & $\begin{array}{l}\text { nary angioplasty, } \\
\text { and } 674 \text { with acut } \\
\text { acute coronary sy }\end{array}$ & $\begin{array}{l}\text { standard deviation. } \\
\text { onary syndrome). } \\
\text { me (analysis of varian }\end{array}$ & Student \\
\hline
\end{tabular}


a value of $p<0.05$ was considered significant. Statistics were calculated using StatView 5.0 software for Windows (Abacus Concepts, Berkley, California).

\section{Results}

Of 4038 consecutive patients presenting with chest pain, 2700 were confirmed by coronary angiography to have cardiac chest pain (Figure 1). Inclusion criteria were met by 2568 of these patients. The median time between onset of chest pain and hospital admission was 2.5 hours.

The patients' clinical characteristics are presented in Table 1; their medical history and use of medications are provided in Table 2. A total of $1339(52.1 \%)$ patients were classified as having stable angina and the remainder as having acute coronary syndrome. The precise diagnoses are shown in Figure 1. We detected significant differences between patients with stable angina and those with acute coronary syndrome in terms of body mass index (BMI), and serum levels of Creactive protein, troponin $\mathrm{I}$, creatine kinase and creatinine ( $p<0.001$ in each case). The impairment of left ventricular function was signifi- cantly more pronounced in patients with acute coronary syndrome than in those with stable angina $(p<0.001)$.

Serum levels of PAPP-A were available for all of the patients. The mean level was $24.6 \pm$ $50.2 \mathrm{mIU} / \mathrm{L}$ (range 4.1-2154.4 mIU/L), and the median was $14.0 \mathrm{mIU} / \mathrm{L}$ (interquartile range 9.3$25.2 \mathrm{mIU} / \mathrm{L}$ ). The broadness of the range of PAPP-A values was driven by one patient, whose level was $2154 \mathrm{mIU} / \mathrm{L}$. The remaining patients had serum levels between 4.1 and $276.2 \mathrm{mIU} / \mathrm{L}$. The PAPP-A values did not differ significantly between male and female patients $(25.0 \pm$ $56.4 \mathrm{mIU} / \mathrm{L}$ and $23.5 \pm 25.6 \mathrm{mIU} / \mathrm{L}$, respectively; $p=0.97$ ). Patients who had acute coronary syndrome presented with slightly higher serum levels of PAPP-A than patients with stable angina $(24.8 \pm 28.5$ v. $24.4 \pm 64.0 \mathrm{mIU} / \mathrm{L}$; $p=0.01$ ). Serum levels of PAPP-A tended to increase with increasing degree of left ventricular dysfunction; however, this finding was driven mainly by patients with severely impaired left ventricular function (mean PAPP-A $30.3 \pm$ $35.3 \mathrm{mIU} / \mathrm{L}$ among patients with left ventricular ejection fraction $<35 \%$ v. $22.8 \pm 26.0 \mathrm{mIU} / / \mathrm{L}$ among those with an ejection fraction $\geq 60 \%$;

Table 2: Medical history and medication use

$\%$ (no.) of patients

\begin{tabular}{|c|c|c|c|c|}
\hline \multirow[b]{2}{*}{ Variable } & \multicolumn{3}{|c|}{$\%$ (no.) of patients } & \multirow[b]{2}{*}{$p$ value* } \\
\hline & $\begin{array}{c}\text { All patients } \\
n=2568\end{array}$ & $\begin{array}{c}\text { Stable angina } \\
n=1339\end{array}$ & $\begin{array}{l}\text { Acute coronary } \\
\text { syndrome } \\
n=1229\end{array}$ & \\
\hline \multicolumn{5}{|l|}{ Medical history } \\
\hline Family history of heart disease & $21.1 \quad(533 / 2526)$ & 23.7 (315/1329) & $18.2(218 / 1197)$ & $<0.001$ \\
\hline Hypertension & $80.9(2044 / 2527)$ & $82.4(1095 / 1329)$ & $79.2(949 / 1198)$ & 0.04 \\
\hline Atrial fibrillation & $12.5(312 / 2499)$ & $12.5(164 / 1313)$ & $12.5(148 / 1186)$ & 0.99 \\
\hline Hyperlipidemia & $65.3(1649 / 2526)$ & $72.2(960 / 1329)$ & $57.6(689 / 1197)$ & $<0.001$ \\
\hline Diabetes mellitus & $33.5(847 / 2526)$ & 33.9 (450/1328) & $33.1(397 / 1198)$ & 0.7 \\
\hline Current smoker & 39.4 (995/2524) & 38.9 (517/1328) & $40.0(478 / 1196)$ & 0.6 \\
\hline Previous MI & $7.0 \quad(65 / 926)$ & $6.9 \quad(37 / 534)$ & $7.1 \quad(28 / 392)$ & 0.9 \\
\hline Previous revascularization & $11.3 \quad(105 / 926)$ & $(69 / 534)$ & $9.2(36 / 392)$ & 0.07 \\
\hline \multicolumn{5}{|l|}{ Medication use } \\
\hline ASA & $65.5(1537 / 2345)$ & $75.2(933 / 1241)$ & $54.7(604 / 1104)$ & $<0.001$ \\
\hline Clopidogrel & $28.8(675 / 2343)$ & $32.9(408 / 1240)$ & $24.2(267 / 1103)$ & $<0.001$ \\
\hline ACE inhibitor or ARB & $59.8(1402 / 2345)$ & $68.4(849 / 1241)$ & $50.1(553 / 1104)$ & $<0.001$ \\
\hline Beta-blocker & $65.0(1522 / 2343)$ & $74.1 \quad(920 / 1241)$ & $54.6(602 / 1102)$ & $<0.001$ \\
\hline Statin & $54.5(1277 / 2344)$ & $65.6(814 / 1240)$ & $41.9(463 / 1104)$ & $<0.001$ \\
\hline Calcium-channel blocker & $18.4(239 / 1300)$ & $20.2(127 / 630)$ & $16.7(112 / 670)$ & 0.1 \\
\hline Diuretic & $38.3(498 / 1300)$ & $40.6 \quad(256 / 630)$ & $36.1(242 / 670)$ & 0.09 \\
\hline Aldosterone antagonist & $2.8 \quad(36 / 1299)$ & $3.3 \quad(21 / 630)$ & $2.2(15 / 669)$ & 0.2 \\
\hline
\end{tabular}


$\left.p_{\text {trend }}=0.003\right)$. In simple regression analysis, PAPP-A levels correlated slightly with serum values of creatine kinase $(r=0.065, p=0.002)$ and troponin I $(r=0.04, p=0.046)$, but not with age, BMI, creatinine level or C-reactive protein level ( $p>0.3$ in each case). Effects of patients' comorbidities and medication use on serum levels of PAPP-A are presented in Table 3.

A total of 203 (7.9\%) of the patients had 245 primary outcome events during the 90 days of follow-up: stent thrombosis (58 events), myocardial (re)infarction (98 events), ischemic stroke (18 events) and cardiovascular-related death (71 events). Patients who experienced a primary outcome had a mean PAPP-A level of 62.0 $\pm 156.4 \mathrm{mIU} / \mathrm{L}$, as compared with $21.4 \pm$ $22.8 \mathrm{mIU} / \mathrm{L}$ among those who did not $(p<$ $0.001)$. No difference in outcome was detected between patients with stable angina and any of the subgroups of patients with acute coronary syndrome ( $\left.p_{\text {trend }}=0.09\right)$.

Several dichotomized and continuous variables were investigated to determine their potential to predict the primary outcome within 90 days of follow-up (Table 4). In the single predictor Cox proportional hazard analysis, the presence of left ventricular dysfunction (dichotomized), the presence of acute coronary syndrome (dichotomized), PAPP-A (dichotomized or continuous), C-reactive protein (dichotomized or continuous), creatine kinase (dichotomized), troponin I (dichotomized or continuous) and creatinine (dichotomized or continuous) all predicted major adverse cardiovascular events, whereas sex, age, BMI, number of affected coronary vessels and attributes from the patients' medical history did not (all $p \geq 0.05$, Table 4). After adjustment for predictors of the primary outcome that were clinically important in the single-predictor model, PAPP-A remained a significant independent predictor of major cardiovascular events (adjusted HR per 1 SD increase in log PAPP-A 1.96, 95\% CI 1.742.21). Other significant predictors in the adjusted model were a history of diabetes mellitus (adjusted HR 1.49, 95\% CI 1.06-2.10) and a history of atrial fibrillation (adjusted HR 0.52, 95\% CI 0.29-0.94) (Table 4).

PAPP-A remained the strongest predictor of major cardiovascular events when we restricted the analysis to patients with stable angina (adjusted HR per 1 SD increase in log PAPP-A $2.15,95 \%$ CI 1.81-2.56) and when we restricted it to patients with acute coronary syndrome (adjusted HR per 1 SD increase in log PAPP-A $1.91,95 \%$ CI $1.48-2.46)$. In the multivariable model including the entire cohort, no material change was noted when we analyzed separately the outcomes myocardial (re)infarction (adjusted HR per 1 SD increase in log PAPP-A $1.89,95 \%$ CI 1.60-2.24), ischemic stroke (adjusted HR per 1 SD increase in log PAPP-A 2.15, 95\% CI $1.51-$ 3.06) and cardiovascular-related death (adjusted HR per 1 SD increase in log PAPP-A 2.06, 95\% CI 1.70-2.49). This finding could not be verified with regard to the outcome stent thrombosis, for which only the presence of left ventricular dysfunction (adjusted HR 2.05, 95\% CI 1.05-3.99) and a medical history of diabetes (adjusted HR $3.33,95 \%$ CI $1.78-6.22$ ) proved to be independently predictive.

Figure 2 shows the Kaplan-Meier survival curves for patients with PAPP-A below and above the best prognostic cut-off of $34.6 \mathrm{mIU} / \mathrm{L}$, adjusted for all variables shown in the multivariable model in Table 4 (adjusted HR 5.28, 95\% CI 3.81-7.31).

Adjusting the main clinical model for the variables that were available only for a limited number of patients (BMI, previous myocardial infarction and previous revascularization) did not change the results with regards to PAPP-A. After adjustment for BMI, PAPP-A remained a significant predictor of the combined primary outcome (adjusted HR per 1 SD increase in log PAPP-A 2.13, 95\% CI 1.83-2.49), with BMI also being

\begin{tabular}{|c|c|c|c|}
\hline \multirow[b]{2}{*}{ Factor } & \multicolumn{2}{|c|}{ Serum PAPP-A level, mean \pm SD } & \multirow[b]{2}{*}{$p$ value } \\
\hline & Factor absent & Factor present & \\
\hline \multicolumn{4}{|l|}{ Medical history } \\
\hline $\begin{array}{l}\text { Family history of heart } \\
\text { disease }\end{array}$ & $24.3 \pm 54.8$ & $26.0 \pm 30.3$ & 0.04 \\
\hline Hypertension & $24.4 \pm 25.8$ & $24.7 \pm 54.8$ & 0.2 \\
\hline Atrial fibrillation & $25.2 \pm 53.6$ & $21.7 \pm 22.8$ & 0.2 \\
\hline Hyperlipidemia & $23.3 \pm 26.5$ & $25.4 \pm 59.6$ & 0.6 \\
\hline Diabetes mellitus & $25.2 \pm 58.4$ & $23.6 \pm 29.4$ & 0.1 \\
\hline Current smoker & $24.8 \pm 61.2$ & $24.4 \pm 27.2$ & 0.1 \\
\hline \multicolumn{4}{|l|}{ Medication use } \\
\hline ASA & $24.6 \pm 29.0$ & $24.7 \pm 60.5$ & 0.2 \\
\hline Clopidogrel & $24.9 \pm 58.9$ & $24.4 \pm 27.6$ & 0.4 \\
\hline ACE inhibitor or ARB & $24.4 \pm 29.7$ & $24.9 \pm 62.5$ & 0.96 \\
\hline Beta-blocker & $25.3 \pm 30.3$ & $24.4 \pm 60.4$ & 0.04 \\
\hline Statin & $26.9 \pm 71.7$ & $22.9 \pm 25.2$ & 0.2 \\
\hline Calcium-channel blocker & $27.0 \pm 70.6$ & $26.0 \pm 32.9$ & 0.8 \\
\hline Diuretic & $27.7 \pm 80.3$ & $25.4 \pm 27.9$ & 0.97 \\
\hline Aldosterone antagonist & $26.8 \pm 66.2$ & $27.5 \pm 24.9$ & 0.3 \\
\hline $\begin{array}{l}\text { Note: } \text { ACE = angiotensin-conve } \\
\text { acetylsalicylic acid, PAPP-A = pr } \\
\text { deviation. } \\
\text { *Student } t \text {-test. }\end{array}$ & $\begin{array}{l}\text { enzyme, } A R B=a \\
\text { ncy-associated pl }\end{array}$ & $\begin{array}{l}\text { ensin-receptor block } \\
\text { protein A, SD = stan }\end{array}$ & \\
\hline
\end{tabular}


independently predictive (adjusted HR per $1 \mathrm{~kg} / \mathrm{m}^{2}$ increase $0.94,95 \%$ CI $0.89-0.99$ ). Adjusting the main model for the number of affected coronary vessels, history of myocardial infarction and previous revascularization showed that the primary diagnosis of acute coronary syndrome, the presence of left ventricular dysfunction, a history of diabetes, a history of atrial fibrillation, a C-reactive protein level above the optimal cut-off and PAPP-A were all predictive of the combined primary outcome (adjusted HR per increase in 1 SD of log PAPP-A 1.95, 95\% CI 1.57-2.42). The number of affected coronary vessels, history of myocardial infarction and previous revascularization were not predictive in this model.

\section{Interpretation}

Our study showed that PAPP-A was an independent predictor of the combined primary outcome of stent thrombosis, myocardial (re)infarction, ischemic stroke and cardiovascular-related death within 90 days among patients presenting with cardiac chest pain. This finding remained true when we restricted the analysis to include either patients with stable angina or those with acute coronary syndrome.

Similar to other metalloproteinases, PAPP-A could be involved in the processing of the extracellular matrix of arterial plaque and in the weakening of the fibrous cap. ${ }^{15}$ However, whether PAPP-A acts in a proinflammatory

Table 4: Association of serum PAPP-A level and other clinical variables with major adverse cardiovascular events within 90 days after presentation with cardiac chest pain

\begin{tabular}{|c|c|c|}
\hline Variable & $\begin{array}{l}\text { Unadjusted HR } \\
\qquad(95 \% \mathrm{Cl})\end{array}$ & $\begin{array}{l}\text { Adjusted } \mathrm{HR}^{*} \\
\qquad(95 \% \mathrm{Cl})\end{array}$ \\
\hline Male sex & $1.23(0.88-1.71)$ & $1.11(0.73-1.69)$ \\
\hline Age, per year increase & $1.00(0.99-1.02)$ & $1.01(0.99-1.02)$ \\
\hline BMI, per unit increase & $0.96(0.91-1.00)$ & \\
\hline Left ventricular dysfunction present & $1.70(1.27-2.27)$ & $1.32(0.93-1.89)$ \\
\hline Acute coronary syndrome diagnosed & $1.36(1.03-1.79)$ & $0.82(0.54-1.27)$ \\
\hline $\begin{array}{l}\text { Coronary artery disease, per } 1 \text { increase in no. of affected } \\
\text { coronary vessels }\end{array}$ & $0.99(0.74-1.32)$ & \\
\hline Only PTCA performed during current admission & $0.64(0.09-4.60)$ & \\
\hline Stent implantation performed during current admission & $3.45(0.48-24.82)$ & \\
\hline Previous MI & $1.77(0.88-3.55)$ & \\
\hline Previous revascularization & $1.62(0.89-2.94)$ & \\
\hline Family history of heart disease & $1.01(0.72-1.42)$ & $1.08(0.71-1.64)$ \\
\hline Hypertension & $0.88(0.62-1.23)$ & $1.04(0.68-1.61)$ \\
\hline Atrial fibrillation & $0.73(0.46-1.18)$ & $0.52(0.29-0.94)$ \\
\hline Hyperlipidemia & $0.89(0.67-1.19)$ & $0.91(0.64-1.30)$ \\
\hline Diabetes mellitus & $1.27(0.96-1.69)$ & $1.49(1.06-2.10)$ \\
\hline Current smoker & $1.09(0.82-1.44)$ & $1.14(0.79-1.65)$ \\
\hline log PAPP-A, per 1 SD increase & $1.99(1.79-2.21)$ & $1.96(1.74-2.21)$ \\
\hline PAPP-A above optimal cutoff (> 34.6 mU/L) & $5.30(4.02-6.98)$ & \\
\hline log C-reactive protein, per 1 SD increase & $1.24(1.06-1.45)$ & \\
\hline C-reactive protein above optimal cutoff ( $>41.2 \mathrm{mg} / \mathrm{L}$ ) & $1.75(1.28-2.40)$ & $1.43(0.97-2.13)$ \\
\hline log Creatine kinase, per 1 SD increase & $1.12(0.98-1.29)$ & \\
\hline Creatine kinase above optimal cutoff (> $207 \mathrm{U} / \mathrm{L}$ ) & $1.51(1.13-2.02)$ & $0.95(0.60-1.52)$ \\
\hline log Troponin I, per 1 SD increase & $1.19(1.05-1.36)$ & \\
\hline Troponin I above optimal cutoff (> $2.07 \mu \mathrm{g} / \mathrm{L}$ ) & $1.70(1.28-2.25)$ & $1.47(0.89-2.44)$ \\
\hline log Creatinine, per 1 SD increase & $1.20(1.07-1.36)$ & \\
\hline Creatinine above optimal cutoff ( $>88.4 \mu \mathrm{mol} / \mathrm{L}$ ) & $1.43(1.07-1.92)$ & $1.23(0.86-1.76)$ \\
\hline \multicolumn{3}{|c|}{$\begin{array}{l}\text { Note: } \mathrm{BMI}=\text { body mass index, } \mathrm{Cl}=\text { confidence interval, } \mathrm{HR}=\text { hazard ratio, } \mathrm{MI}=\text { myocardial infarction, PAPP-A = pregnancy- } \\
\text { associated plasma protein } \mathrm{A}, \mathrm{PTCA}=\text { percutaneous transluminal coronary angioplasty, } \mathrm{SD}=\text { standard deviation. } \\
\text { *Adjusted for all other variables in the table. For variables that were included twice in the unadjusted model (as log and } \\
\text { continuous variables), the variable with the higher level of significance in the unadjusted model, as judged by the } \chi^{2} \text { value, was } \\
\text { chosen for the multivariable model. }\end{array}$} \\
\hline
\end{tabular}


sense or exerts inflammatory suppressor activity is unclear. ${ }^{15}$ Also unclear is whether insulin-like growth factor-1, whose availability is increased by PAPP-A, is an anti- or a pro-atherogenic molecule. The fact that only a minority of studies have shown a correlation between PAPP-A and $\mathrm{C}$-reactive protein values casts further doubt on the argument that PAPP-A plays a role in inflammatory reactions. ${ }^{16}$ Such a correlation was not noted in our study.

Our findings support the results of earlier studies that suggested PAPP-A as a marker of unstable atherosclerotic plaques, the first of which was published in 2001. ${ }^{12}$ In a study by Cosin-Sales and colleagues involving 396 patients with stable angina, 289 of whom had significant coronary artery disease, patients who had complex lesions had higher serum PAPP-A levels than those who did not. ${ }^{17}$ Lund and colleagues ${ }^{18}$ found that a PAPP-A level above the cut-off of $2.9 \mathrm{mIU} / \mathrm{L}$ and a C-reactive protein level above the cutoff of $2.0 \mathrm{mg} / \mathrm{L}$ predicted cardiovascular death, myocardial infarction or the need for revascularization within 6 months of follow-up. Heeschen and colleagues analyzed PAPP-A levels in 547 patients with angiographically validated acute coronary syndrome and 644 heterogenous patients presenting with acute chest pain. ${ }^{19}$ They found that PAPP-A (optimal cut-off $12.1 \mathrm{mIU} / \mathrm{L}$ ) was an independent predictor of adverse outcomes in both subgroups of patients.

The difference between the optimal cut-off value in our study and the one calculated by Heeschen and colleagues is probably due to the difference in assays used and length of followup periods. Not all assays developed for the detection of PAPP-A in prenatal screening may be suitable for use in patients with coronary artery disease..$^{20}$ Indeed, antibodies used in assays for PAPP-A are all raised by immunization of mice with PAPP-A isolated from human pregnancy serum. However, unlike PAPP-A in patients with coronary artery disease, PAPP-A in pregnancy circulates as a complex with the proform of eosinophil major basic protein (proMBP). Qin and colleagues stated that assays using antibodies against only proMBP fail to detect PAPP-A in patients with acute coronary syndrome. ${ }^{20}$ Although the assay used in our study was developed for use in prenatal screening, the fact that PAPP-A levels were detectable in all of the patients supports the view that the assay correctly identified PAPP-A levels in both patient subgroups.

Several authors have investigated the value of PAPP-A for predicting unstable athero-

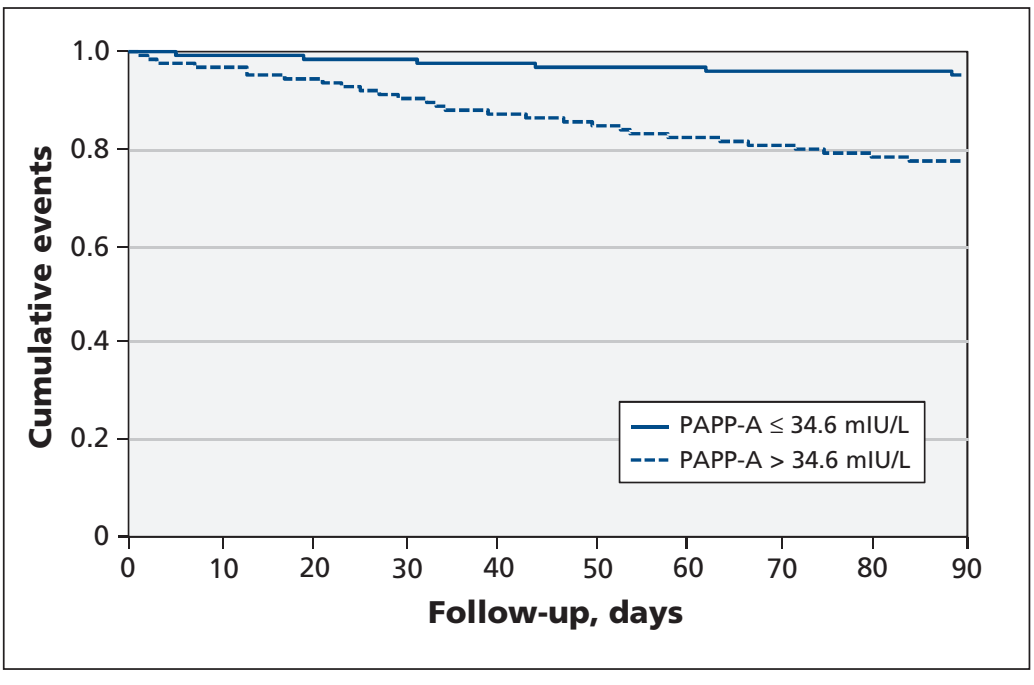

Figure 2: Kaplan-Meier curves for time to primary outcome (combined outcome of stent thrombosis, myocardial [re]infarction, ischemic stroke or cardiovascular-related death) among patients presenting with cardiac chest pain whose pregnancy-associated plasma protein A (PAPP-A) level was below or above the optimal prognostic cut-off value of $34.6 \mathrm{mIU} / \mathrm{L}$ (defined as the highest product of sensitivity times specificity).

sclerotic plaque using either single $16,17,21,22$ or ser$\mathrm{ial}^{23-25}$ measurements, even in patients receiving hemodialysis. ${ }^{26}$ Studies have consistently shown higher PAPP-A levels in patients with acute coronary syndrome or multivessel coronary artery disease than in patients with stable angina or single-vessel disease. ${ }^{20,27,28}$ Our study also showed higher levels in patients with acute coronary syndrome than in those with stable angina.

\section{Limitations}

We analyzed PAPP-A values only from serum samples obtained at baseline. Follow-up samples were not available for our patients. We therefore cannot exclude that peak or follow-up PAPP-A values may have better (or worse) predictive value. In addition, not all patients who present with cardiac chest pain will eventually undergo cardiac catheterization; future studies need to show whether our findings can be applied to these patients as well. Further, we cannot exclude whether PAPP-A might be a better predictor of stent thrombosis if serum samples were drawn just after the procedure; however, in this case, the use of heparin may interfere with PAPP-A assessment. Even though PAPP-A had originally been suggested as a marker of unstable atherosclerotic plaques, ${ }^{12}$ our study did not provide direct biological evidence of plaque instability. Another limitation is that we measured total PAPP-A, not the free form. Findings from a previous study suggested that the free form is a stronger predictor of cardiovascular diseases. ${ }^{29}$ Although our study had a 
large cohort, it was conducted in a single centre. A multinational, multicentre study is needed to validate our results.

\section{Conclusion}

Higher levels of serum PAPP-A were independently associated with an increased short-term risk of cardiovascular events in patients presenting with cardiac chest pain. Further studies are required to validate the use of PAPP-A in routine clinical practice to predict future cardiovascular events. If these studies are successful, PAPP-A measurements could play a role in reducing morbidity and mortality from coronary disease.

\section{References}

1. World Health Organization. The top 10 causes of death. Geneva (Switzerland): The Organization; 2011. Available: www.who.int /mediacentre/factsheets/fs310/en/index.html (accessed 2012 Nov. 28).

2. Bassand JP, Hamm CW, Ardissino D, et al. Guidelines for the diagnosis and treatment of non-ST-segment elevation acute coronary syndromes. Eur Heart J 2007;28:1598-660.

3. Antman EM, Tanasijevic MJ, Thompson B, et al. Cardiac-specific troponin I levels to predict the risk of mortality in patients with acute coronary syndromes. N Engl J Med 1996;335:1342-9.

4. Galvani M, Ottani F, Ferrini D, et al. Prognostic influence of elevated values of cardiac troponin I in patients with unstable angina. Circulation 1997;95:2053-9.

5. Hamm CW, Goldmann BU, Heeschen C, et al. Emergency room triage of patients with acute chest pain by means of rapid testing for cardiac troponin T or troponin I. N Engl J Med 1997;337: 1648-53.

6. Lawrence JB, Oxvig C, Overgaard MT, et al. The insulin-like growth factor (IGF)-dependent IGF binding protein-4 protease secreted by human fibroblasts is pregnancy-associated plasma protein-A. Proc Natl Acad Sci U S A 1999;96:3149-53.

7. Laursen LS, Overgaard MT, Søe R, et al. Pregnancy-associated plasma protein-A (PAPP-A) cleaves insulin-like growth factor binding protein (IGFBP)-5 independent of IGF: implications for the mechanism of IGFBP-4 proteolysis by PAPP-A. FEBS Lett 2001;504:36-40.

8. Qin QP, Wittfooth S, Pettersson K. Measurement and clinical significance of circulating PAPP-A in ACS patients. Clin Chim Acta 2007;380:59-67.

9. Gall SA, Halbert SP. Antigenic constituents in pregnancy plasma which are undetectable in normal non-pregnant female or male plasma. Int Arch Allergy Appl Immunol 1972;42:503-15.

10. Barrett SL, Bower C, Hadlow NC. Use of the combined firsttrimester screen result and low PAPP-A to predict risk of adverse fetal outcomes. Prenat Diagn 2008;28:28-35.

11. Wøjdemann KR, Larsen SO, Rode L. First trimester Down syndrome screening: distribution of markers and comparison of assays for quantification of pregnancy-associated plasma protein-A. Scand J Clin Lab Invest 2006;66:101-11.

12. Bayes-Genis A, Conover CA, Overgaard MT, et al. Pregnancyassociated plasma protein A as a marker of acute coronary syndromes. N Engl J Med 2001;345:1022-9.

13. Anderson JL, Adams CD, Antman EM, et al. ACC/AHA 2007 guidelines for the management of patients with unstable angina/non-ST-elevation myocardial infarction: a report of the American College of Cardiology/American Heart Association Task Force on Practice Guidelines (Writing Committee to Revise the 2002 Guidelines for the Management of Patients With Unstable Angina/Non-ST-Elevation Myocardial Infarction) developed in collaboration with the American College of Emergency Physicians, the Society for Cardiovascular Angiography and Interventions, and the Society of Thoracic Surgeons endorsed by the American Association of Cardiovascular and Pulmonary Rehabilitation and the Society for Academic Emergency Medicine. J Am Coll Cardiol 2007;50:e1-157.

14. Davey MW, Teisner B, Sinosich M, et al. Interaction between heparin and human pregnancy-associated plasma protein $\mathrm{A}$ (PAPP-A): a simple purification procedure. Anal Biochem 1983;131:18-24.
15. Laterza OF. PAPP-A: a marker of plaque instability. Is it ready for prime time? Future Cardiol 2005;1:495-500.

16. Thorn EM, Khan IA. Pregnancy-associated plasma protein-A an emerging cardiac biomarker. Int J Cardiol 2007;117:370-2.

17. Cosin-Sales J, Christiansen M, Kaminski P, et al. Pregnancyassociated plasma protein $\mathrm{A}$ and its endogenous inhibitor, the proform of eosinophil major basic protein (proMBP), are related to complex stenosis morphology in patients with stable angina pectoris. Circulation 2004;109:1724-8.

18. Lund J, Qin QP, Ilva T, et al. Circulating pregnancy-associated plasma protein A predicts outcome in patients with acute coronary syndrome but no troponin I elevation. Circulation 2003; 108:1924-6.

19. Heeschen C, Dimmeler S, Hamm CW, et al.; CAPTURE Study Investigators. Pregnancy-associated plasma protein-A levels in patients with acute coronary syndromes: comparison with markers of systemic inflammation, platelet activation, and myocardial necrosis. J Am Coll Cardiol 2005;45:229-37.

20. Qin QP, Kokkala S, Lund J, et al. Immunoassays developed for pregnancy-associated plasma protein-A (PAPP-A) in pregnancy may not recognize PAPP-A in acute coronary syndromes. Clin Chem 2006;52:398-404

21. McCann CJ, Glover BM, Menown IB, et al. Prognostic value of a multimarker approach for patients presenting to hospital with acute chest pain. Am J Cardiol 2009; 103:22-8.

22. Hájek P, Macek M, Hladíková M, et al. Pregnancy-associated plasma protein $\mathrm{A}$ and proform eosinophilic major basic protein in the detection of different types of coronary artery disease. Physiol Res 2008;57:23-32.

23. Iversen KK, Dalsgaard M, Teisner AS, et al. Usefulness of pregnancy-associated plasma protein $\mathrm{A}$ in patients with acute coronary syndrome. Am J Cardiol 2009;104:1465-71.

24. Iversen KK, Teisner AS, Teisner B, et al. Pregnancy associated plasma protein A, a potential marker for vulnerable plaque in patients with non-ST-segment elevation acute coronary syndrome. Clin Biochem 2009;42:828-34

25. Iversen KK, Dalsgaard M, Teisner AS, et al. Pregnancy-associated plasma protein-a, a marker for outcome in patients suspected for acute coronary syndrome. Clin Biochem 2010;43: 851-7.

26. Etter C, Straub Y, Hersberger M, et al. Pregnancy-associated plasma protein-A is an independent short-time predictor of mortality in patients on maintenance haemodialysis. Eur Heart $J$ 2010;31:354-9.

27. Liu ZY, Zhang JY, Sun TW, et al. Levels of pregnancy-associated plasma protein $\mathrm{A}$ in patients with coronary artery disease. Clin Invest Med 2008;31:E85-9.

28. Cosin-Sales J, Kaski JC, Christiansen M, et al. Relationship among pregnancy associated plasma protein-A levels, clinical characteristics, and coronary artery disease extent in patients with chronic stable angina pectoris. Eur Heart J 2005;26: 2093-8.

29. Lund J, Wittfooth S, Qin QP, et al. Free vs total pregnancyassociated plasma protein A (PAPP-A) as a predictor of 1-year outcome in patients presenting with non-ST-elevation acute coronary syndrome. Clin Chem 2010;56:1158-65.

Competing interests: Stephan von Haehling has been a paid consultant to Thermo Fisher Scientific, Solartium Dietetics, Professional Dietetics, Pfizer, Respicardia and Vifor Pharma; he has received payment from the Heart Failure Association of the European Society of Cardiology to develop educational presentations and travel support from Novartis Pharma; his institution has received a research grant from Vifor Pharma. Stefan Anker has been a paid consultant to Amgen, Bosch Healthcare, Professional Dietetics, Relypsa, Thermo Fisher Scientific, GlaxoSmithKline, Novartis, LoneStar Heart and SHL Telemedicine; he has received speaker fees from Novartis; he holds patents with BRAHMS AG, Charité Berlin and Imperial College for cachexia therapy; and his institution has received a research grant from Vifor Pharma. No competing interests declared by the other authors.

Affiliations: From the Division of Applied Cachexia Research (von Haehling, Doehner, Anker), Department of Cardiology, Charité Medical School, Campus VirchowKlinikum, Berlin, Germany; the Center for Cardiovascular Research (von Haehling), Charité Medical School, Campus Mitte, Berlin, Germany; the Center for Stroke Research Berlin (Doehner), Charité Medical School, Berlin, Germany; 
the Department of Cardiology (Jankowska, Ponikowski), Military Hospital, Wroclaw, Poland; the Medizinische Klinik III (Stellos, Gawaz, Bigalke), Department of Cardiology and Circulatory Diseases, Eberhard-Karls University Tübingen, Tübingen, Germany; the Cardiovascular Section (Puntmann), Division of Experimental Medicine, Imperial College London, London, UK; the Division of Imaging Sciences and Biomedical Engineering (Puntmann, Nagel, Bigalke), School of Medicine, King's College London, The Rayne Institute, London, UK; and the Centre for Clinical and Basic Research (Anker), IRCCS San Raffaele Pisana, Rome, Italy

Contributors: Stephan von Haehling conceived the hypothesis, analyzed the data and wrote the first draft of the manuscript. Wolfram Doehner, Ewa Jankowska, Piotr Ponikowski, Stefan Anker, Valentina Puntmann, Meinrad Gawaz and Eike Nagel provided critical input at all stages and substantially revised the paper. Boris Bigalke and Konstantinos Stellos contributed to the accumulation, analysis and interpretation of the data and substantially revised the paper. All of the authors approved the final version of the manuscript submitted for publication. Stephan von Haehling and Boris Bigalke are the guarantors of the study.

Funding: This study was supported in part by the Deutsche Forschungsgemeinschaft (German Research Foundation) (Clinical Research Unit 274: Platelets - Molecular Mechanisms and Translational Implications). The study sponsors had no role in the design of the study, the collection, analysis or interpretation of data, the writing of the report or the decision to submit the article for publication.

Acknowledgement: This article is dedicated to the memory of Dr. Jana Papassotiriou $\mathrm{PhD}$, who paved the initial way in making this research project possible. 